\title{
Practitioners' Perspective on Software Project Management Education
}

Maria Lydia Fioravanti, University of São Paulo (ICMC-USP), mlfioravanti@usp.br Antonio Cesar Amaru Maximiano (ret), University of São Paulo (FEA-USP), maximin@usp.br

Ellen Francine Barbosa, University of São Paulo (ICMC-USP), francine@ icmc.usp.br

Abstract: Despite Software project management (SPM) being one of the most relevant topics in the area of software engineering that should be addressed in computing programs, SPM skills of recent graduates are not satisfactory yet. In this context, besides being important to know there are skill deficiencies, we also need to gather specific information on how to adjust and improve the education on the corresponding topics. In this paper we attempt to identify what knowledge deficiencies in SPM can persist after a student graduates from a computing degree program. We surveyed practitioners that graduated and worked as software project managers to gather the knowledge deficiencies from the industry perspective. In general, the results indicated that there is a number of professionals who seeks postgraduate programs to fill the deficiencies of the undergrad programs.

Keywords: Software Project Management, SPM, SPM Education, SPM Skills, Knowledge Deficiencies

Resumo: Apesar de o gerenciamento de projetos de software (GPS) ser um dos tópicos mais relevantes na área de engenharia de software que devem ser abordados em programas de computação, as habilidades de GPS dos recém-formados ainda não são satisfatórias. Nesse contexto, além de ser importante saber que existem deficiências de habilidades, também é necessário reunir informações específicas sobre como ajustar e aprimorar o ensino nos tópicos correspondentes. Neste artigo, são identificadas quais deficiências de conhecimento em GPS podem persistir depois que um aluno se forma em um programa de graduação em computação. As pesquisas foram realizadas com profissionais que se formaram e trabalharam como gerentes de projeto de software para reunir as deficiências de conhecimento da perspectiva da indústria. Em linhas gerais, os resultados indicaram que há um número de profissionais que buscam programas de pós-graduação para suprir as deficiências dos programas de graduação.

Palavras-chave: Gestão de Projetos de Software, GPS, Ensino de GPS, Habilidades gerenciais, Deficiências de conhecimento

\section{Introduction}

Projects are a key way to create value and benefits in organizations. In today's business environment, organizational leaders need to be able to manage with tighter budgets, shorter timelines, scarcity of resources, and rapidly changing technology (PMI, 2017). According

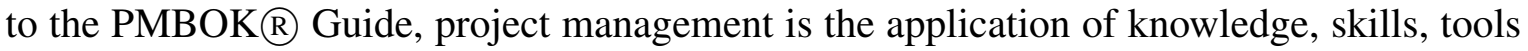
and techniques to project activities to meet the project requirements (PMI, 2017). According to Kerzner (2013), the achievement of excellence in project management is not possible without a repetitive process that can be used in each project. Such process corresponds to the project management methodology, encompassing the necessary knowledge, techniques, and instruments.

Teaching students effectively any subject is a challenging endeavor by itself. Another issue that may discourage graduate and undergraduate students is the disassociation V. $17 \mathrm{~N}^{\mathrm{o}} 3$, dezembro, 2019 RENOTE DOI: 
between theory and practice. According to the body of knowledge in Computer Science version CS2013 (ACM/IEEE-CS, 2013), several areas of Computer Science should be addressed throughout the undergraduate (UG) degree program. Following the structure of areas, units and topics proposed by ACM/IEEE, the Software Project Management (SPM) unit is part of the Software Engineering (SE) area and contain mandatory topics to be addressed.

Frequently, the subject of project management is approached in a theoretical way. However, there is a set of challenges that researchers, curriculum designers and instructors should address in order to improve SE, and consequently SPM education (LETHBRIDGE $e t$ al. 2007). One aspect that stands out is that the education should have a closer relation with practice. However, when comparing the de facto SE education against industry expectations, it is possible to note that students are graduating from computing programs with knowledge deficiencies in several areas (RADERMACHER; WALIA, 2013).

Radermacher and Walia (2013) pointed out in which areas graduates most frequently do not meet industry expectations, including technical skills (such as project management) and also soft skills (such as written and oral communication, teamwork, leadership, etc.). Thus, it is useful to specifically investigate the knowledge deficiencies in project management, but aiming more granularity, i.e., investigating it in terms of technical and soft skills that should be addressed.

Considering this scenario, in this paper we investigated what knowledge deficiencies in software project management education still persist after a student graduates from a computing program. We surveyed practitioners that graduated and worked as software project managers to gather the knowledge deficiencies from the industry point of view. Results can help to shed light on how to improve the teaching of software project management and to avoid possible knowledge gaps with which the students might graduate.

The remainder of the paper is organized as follows. In Section 2 , we discuss studies which compare SE and PM education, industry needs and how these studies are related to the one described in this paper. In Section 3, we discuss the survey design of this study. Results are presented in Section 4 and discussed in Section 5. Then, Section 6 analyzes the threats to validity. Finally, we draw conclusions and provide directions for future work in Section 7 .

\section{Related Work}

There are several studies concerned with the comparison between what is covered by computing education and what software industry really needs. This kind of investigation is relevant because there is a high demand for qualified software professionals. Attempting to align computing education with industry practices is a good way to address this demand.

Moreno et al. (2012) compared curricular guidelines and professional profiles aiming to identify the relationships between recommended computing competences and relevant skills to software professionals. Their results indicated that even the curriculum guidelines do not cover all the basic knowledge necessary for professionals to carry out their work in industry. This means that even when implemented in specific colleges or universities, students still graduate with knowledge deficiencies.

Likewise, Radermacher and Walia (2013) conducted a systematic literature review looking for knowledge deficiencies reported by previous studies. Based on the studies retrieved, the authors stated that a gap in project management was identified in a large number of publications spanning computer science, information technology and information sysRENOTE 
tems. They also found out that employers were not satisfied with the project management skills of recent graduates.

Kitchenham et al. (2005) also performed a similar survey in the context of UK universities. The topic of Software Project Management was among the topics considered more important to practitioners and also among professional seek to learn after graduating. The paper indicated that project management was one of the most important topics for curriculum change as there was a large gap between what developers knew when they had graduated and what they needed to know for their current job.

In a more recent perspective, Tuzun, Erdogmus and Ozbilgin (2018) analyzed if computer science and engineering graduates are ready for software industry. The authors made some observations regarding software project management. After conducting the study, the authors applied a questionnaire in which the students chose Software Project Management as the least helpful content. A possible explanation for the apparent, relative lower impact of this knowledge area early in the students' careers could be attributed to the advanced nature of the topic: project management is a skill that they are more likely to need later in their careers, and none of the participants assumed a project management responsibility during their first year.

Considering the aforementioned, we conducted a survey that focused in gathering the knowledge deficiencies in software project management from the industry point of view, as described next.

\section{Design of the Study}

A survey is a comprehensive research method for collecting information to describe, compare or explain knowledge, attitudes and behavior (KITCHENHAM; PFLEEGER, 2008). Kasunic (2005) proposed a seven-stage process to conduct a survey, shown in Figure 1. which was adopted in our survey.

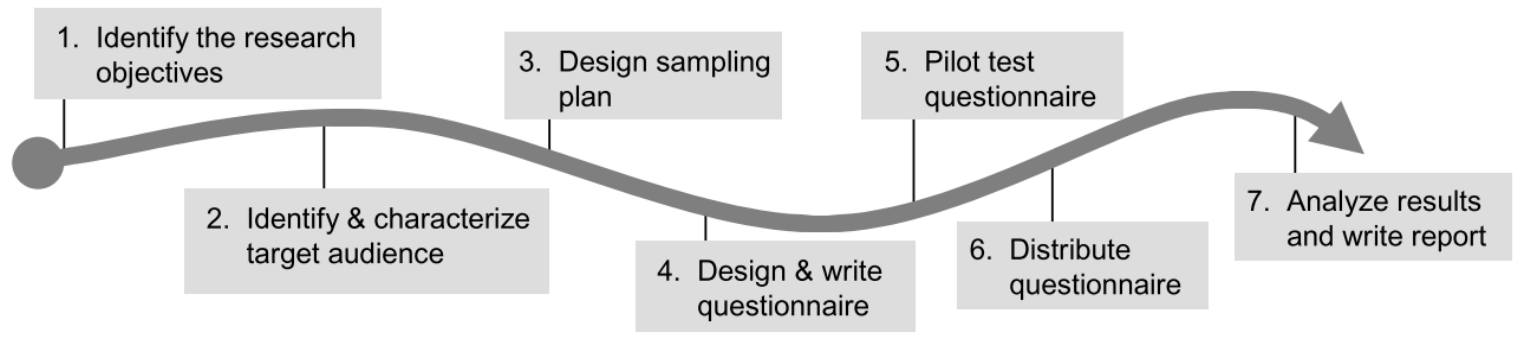

Figure 1. Overview of the seven-stage survey research process (KASUNIC, 2005)

The main goal of this survey is to characterize Project Management Education delivered to the current software project managers according to industry needs. In this sense, to establish the specific goals of the survey we used the Goal-Question-Metric approach proposed by Basili (1992). The specific goals of the survey are the following:

- Characterize the educational and professional profile of software project managers.

- Identify the knowledge deficiencies in Project Management topics that graduates from computing programs have with respect to industry needs

- Identify the main technical and soft skills of software project managers.

The population under study is Software Project Managers. To collect data, a webbased questionnaire ${ }^{1}$ was designed with questions that map to the defined research questions.

$1\langle$ http://bit.ly/renote-survey-questionnaire

V. $17 \mathrm{~N}^{\mathrm{o}}$ 3, dezembro, 2019

RENOTE

DOI: 
To avoid ambiguously and poorly-worded questions, we pilot-tested our questionnaire before sending to participants.

As the results of this study will provide input for the proposal of an approach to teach SPM, we expect to generalize them; therefore our sample must be a probability sample (KASUNIC, 2005). However, we do not have a list with every subject of our population, so we decided to select as many subjects as we can that match our criteria previously established. We recruited respondents by sending emails with a link to the web-based questionnaire. We took advantage of mailing lists for graduates from some universities and also social media groups of project managers. We also sent a reminder one week after the distribution of questionnaires and one day before the deadline to increase response rate.

\section{Results}

In this section we present the survey results. We received 40 responses from software project managers in total.

\subsection{Educational and Professional Profile}

Aiming to get an overview of the educational and professional context from which we are identifying the knowledge deficiencies, respondents were firstly asked to provide their undergraduate degree(s) program(s). Although we had 40 respondents, two of them had two undergraduate degrees, so the total results of 42 programs are shown in Figure 2. Computer Science represents the predominant degree (43\%) among the respondents, followed by Information Systems (19\%) and Computer Engineering (14\%). Some respondents $(11.11 \%)$ mentioned other degree programs in Computing, such as Data Processing and Systems Analysis. Other respondents also mentioned degrees in Business programs (10\%) or other Math, Science and Engineering programs (5\%). One respondent also mentioned a degree in $\mathrm{Hu}-$ manities. In total, degrees in Computing programs represent the majority (83\%) of the chosen programs.

Still regarding the practitioners' educational profile, we asked if they have (or are currently pursuing) a postgraduate degree. Figure 3 shows that $80 \%$ of our practitioners have (or are currently pursuing) a postgraduate degree, $60 \%$ being a specialization, $13 \%$ both specialization and masters, and 7\% masters. Also 20\% answered they do not have a postgraduate degree.

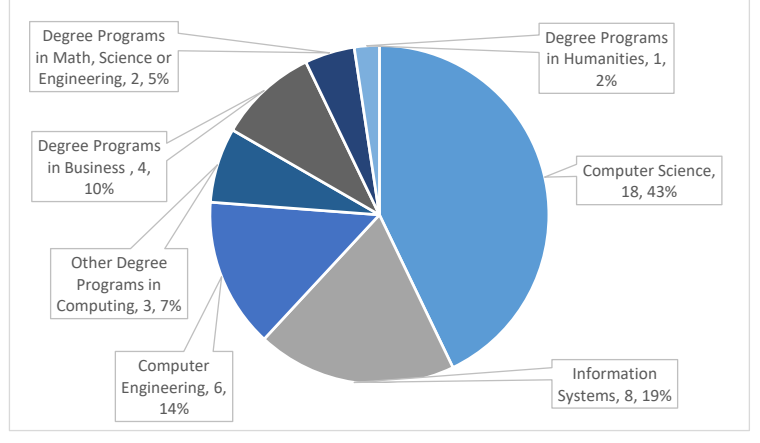

Figure 2. Practitioners' undergraduate degree program

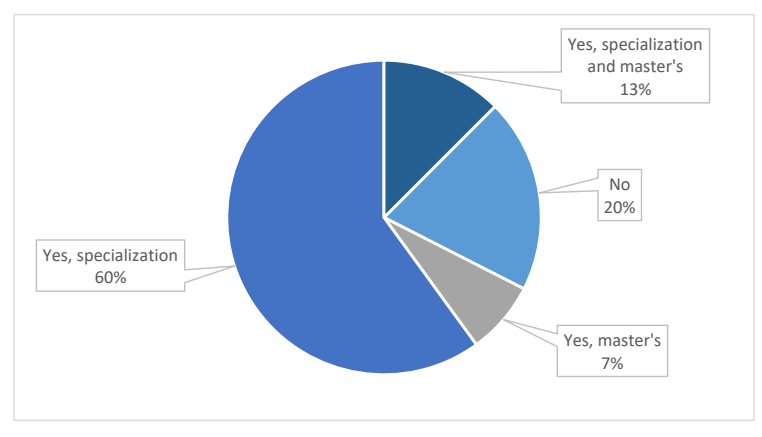

Figure 3. Practitioners' postgraduate degree types

In this scenario, we mapped the areas of such postgraduate courses, so that these data provided subsidies on the technical and managerial knowledge of the practitioners. Figure 4 shows the most chosen programs by the practitioners. The three most chosen are Project V. $17 \mathrm{~N}^{\circ}$ 3, dezembro, 2019 RENOTE 
Management, Business Administration and Business Management. It is worth mentioning that some practitioners have two or more postgraduate courses.

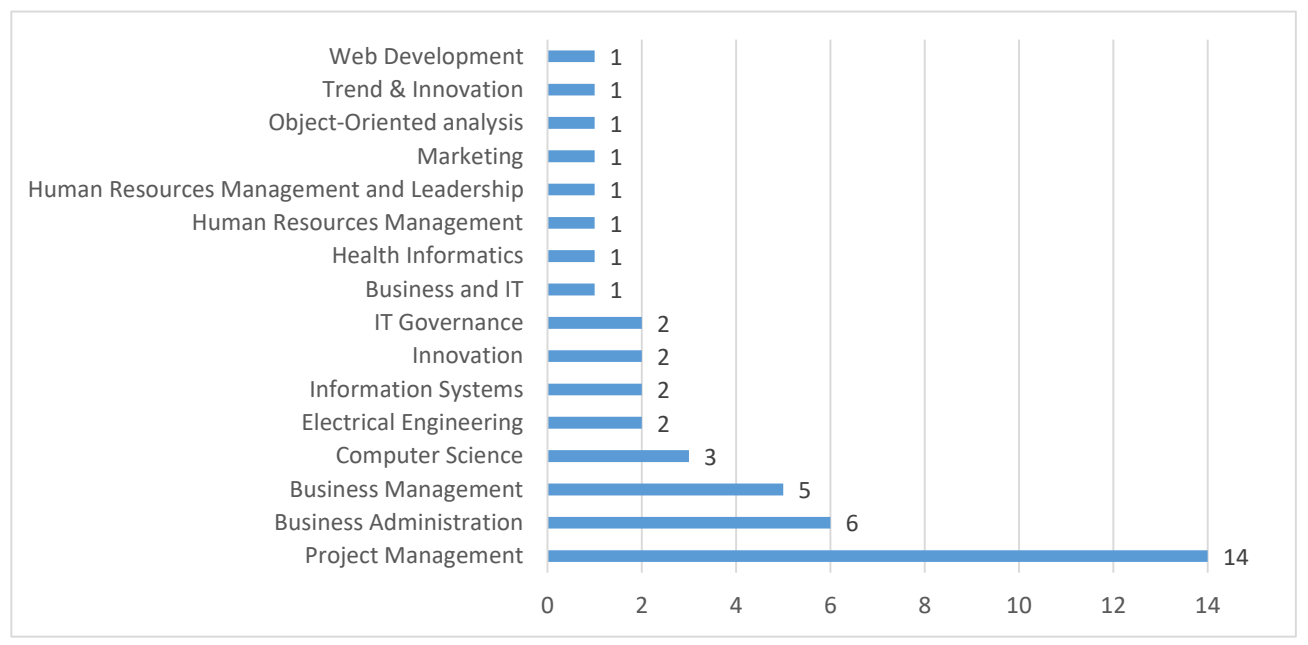

Figure 4. Practitioners' postgraduate degree program

We also tried to understand the reason why the practitioners attended the chosen programs. As shown in Figure 5, the majority (84\%) aimed at complementing the knowledge of undergraduation course, while the remainder $16 \%$ attended the program as a prerequisite to become project manager.

Next, in order to understand the practitioners' professional background, they were asked about their current project manager level. Figure 6 shows that $60 \%$ of the practitioners are experienced managers, being a senior project manager, while $25 \%$ of them are full project managers and, finally, the remainder $15 \%$ are junior project managers.

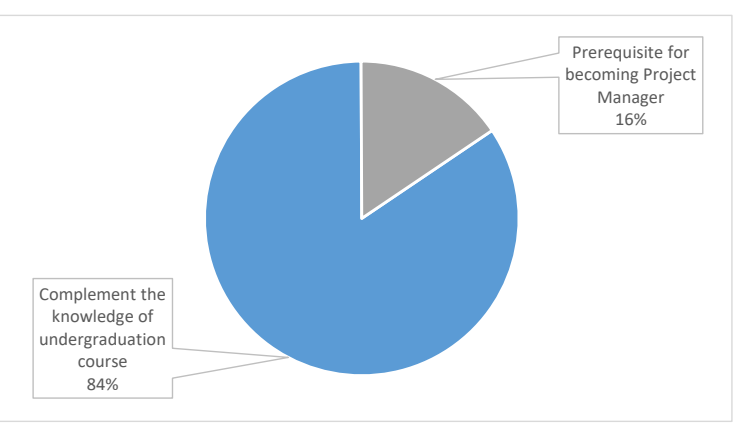

Figure 5. Practitioners' reason to attend the program

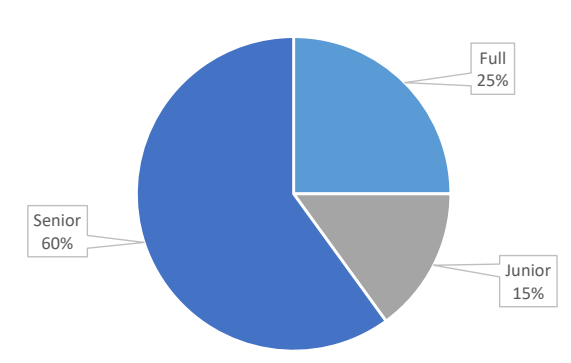

Figure 6. Project manager level

The distribution of years to become a project manager is given in Figure 7. The average was 4.91 years after graduation to become a project manager, while the median was 5 years. One interesting way to analyze these results is by mapping the data of those who became a project manager in up to three years after graduation. From the 15 practitioners, 4 of them (26.7\%) graduated from degree programs in Business. Also 60\% of such practitioners attended a postgraduate degree program.

Next, in order to understand how experienced in Software Project Management the practitioners were, they were asked their year of experience as project manager, showed in Figure 8 . The average was 8.58 years of experience. There was a considerable variability in practitioners experience and this can positively contribute to the study, since professionals at different moments of their career can bring complementary contributions to the results. 


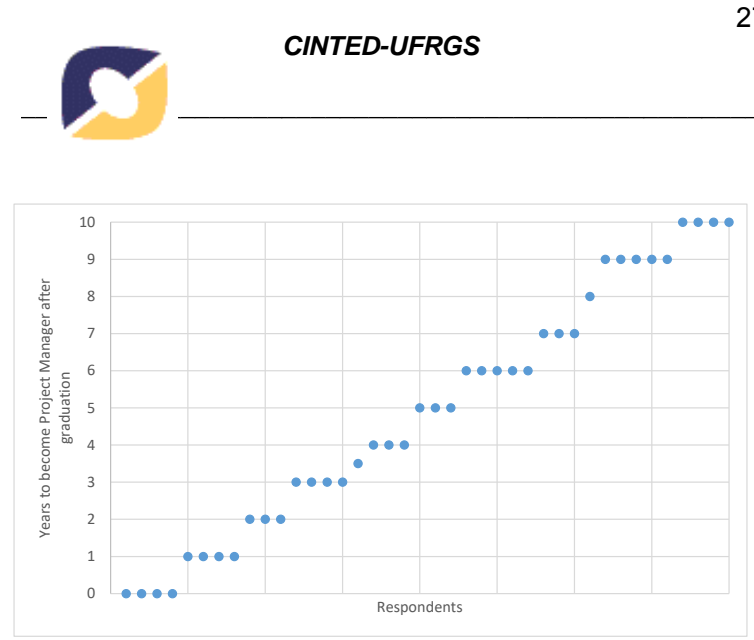

Figure 7. Years to become Project Manager after graduating

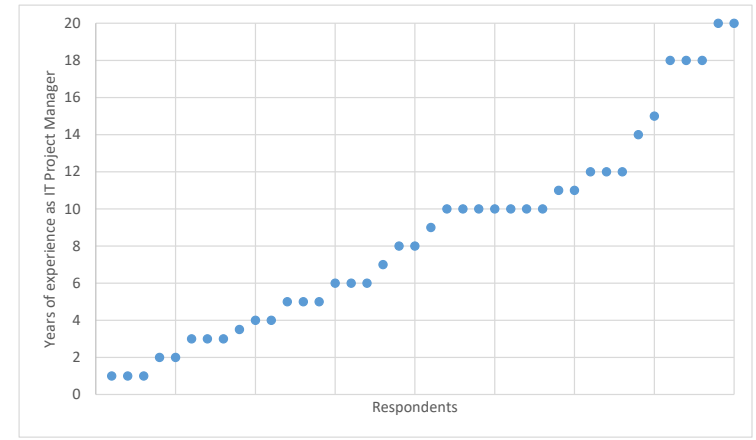

Figure 8. Years of experience as Software Project Manager

Finally, we wanted to know whether the respondent had a PMP Certification ${ }^{2}$ and the reasons for this. Figure 9 shows that $40 \%$ of the practitioners earned a PMP Certification, while the other $60 \%$ did not. Concerning the reasons to earn PMP Certification, Figure 10 shows that from the 16 PMP-Certified practitioners, 4 of them (45\%) earned it as a market requirement. The remainder $75 \%$ were not asked to have this certification as prerequisite to act as a project manager.

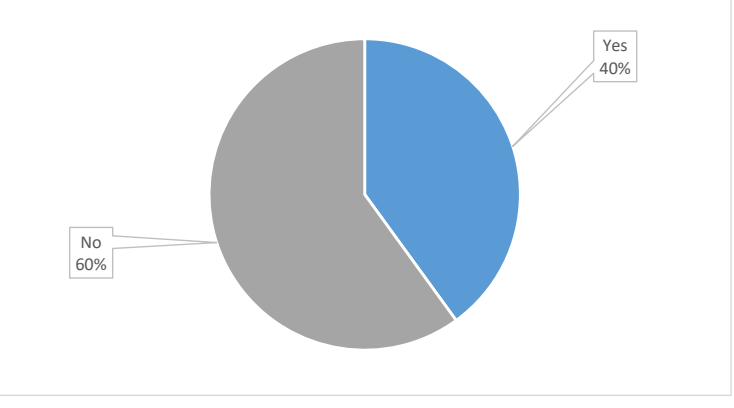

Figure 9. PMP-Certified Practitioners

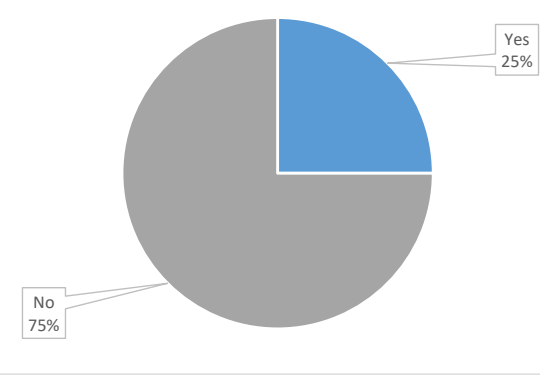

Figure 10. PMP Certification as a market requirement

\subsection{Knowledge Deficiencies on Project Management}

As discussed in Section 3, the survey had a set of questions to identify knowledge deficiencies in Software Project Management Education. Since we could not objectively evaluate for each respondent what he/she knew when graduated and compare this with the knowledge expected to act as a project manager, we asked their impressions about the teaching of this subject.

First, they were asked if during their undergraduate degree they attended a course dedicated to the subject of Project Management. Figure 11 shows that 18 practitioners (45\%) had a course dedicated to Project Management, that is, more than half of the practitioners learned Project Management content at a high level in another course or they were simply never presented such concepts.

For those practitioners who attended a Project Management course during undergraduation, we also asked some complementary questions. First, they were asked if the course they attended covered all the technical content of Project Management. 12(a) shows that more than half of the practitioners (61\%) "Strongly Disagree" or "Disagree". The percentage of practitioners that "Agree" or "Strongly Agree" represents 17\%. Similarly, they

\footnotetext{
${ }^{2}$ PMP (Project Management Professional) is an internationally recognized professional designation offered by the Project Management Institute.

V. $17 \mathrm{~N}^{\mathrm{o}}$ 3, dezembro, 2019

RENOTE

DOI:
} 


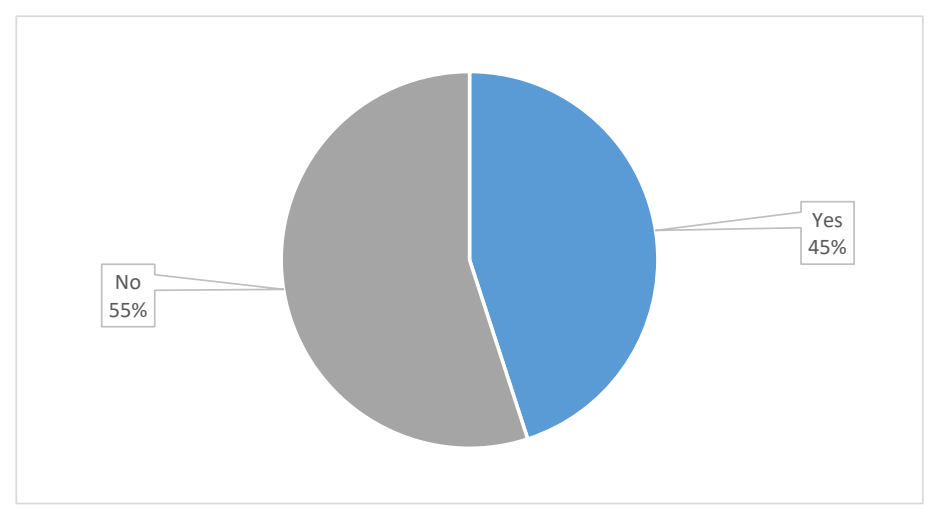

Figure 11. Attended a PM course during UG program

were asked if the course covered practical activities of Project Management. As shown in 12(b), in this case, the percentage of practitioners that "Strongly Disagree" or "Disagree" is higher than for the previous question (72\%). Finally, we also asked if the course enabled the development of their soft skills to act as project manager. 12(c)] shows that the percentage of practitioners who "Strongly Disagree" or "Disagree" is 78\%, even higher than when compared to hands-on activities.

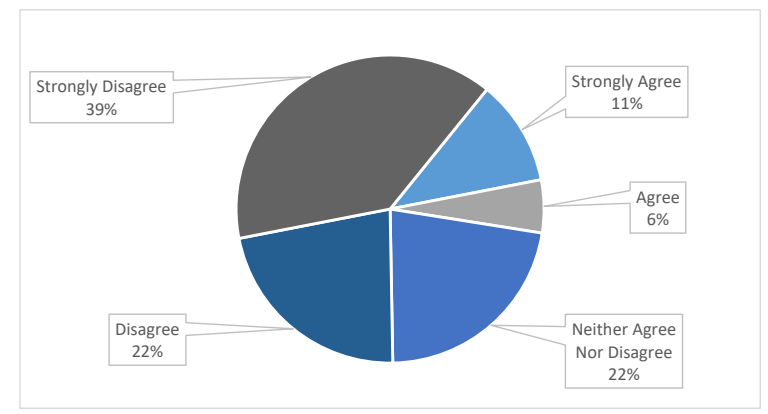

(a) Technical content

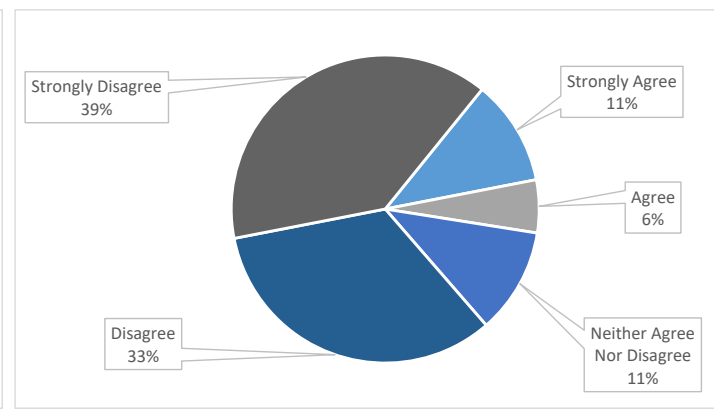

(b) Hands-on activities

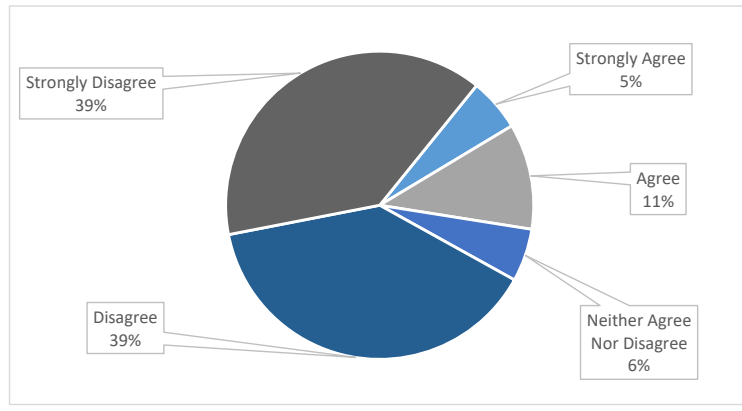

(c) Development of soft skills

Figure 12. Course of Project Management

Considering their educational and professional experience, practitioners were asked if they agreed that technology undergraduate degree programs should have a course dedicated to the teaching of Software Project Management. Figure 13 shows that the majority $(80 \%)$ "Agree" or "Strongly Agree". The remainder $20 \%$ of practitioners were divided into "Neither Agree Nor Disagree" and "Disagree".

We also asked them to briefly report what should be covered in this course. We analyzed the responses and identified the main points to which they drew attention: 


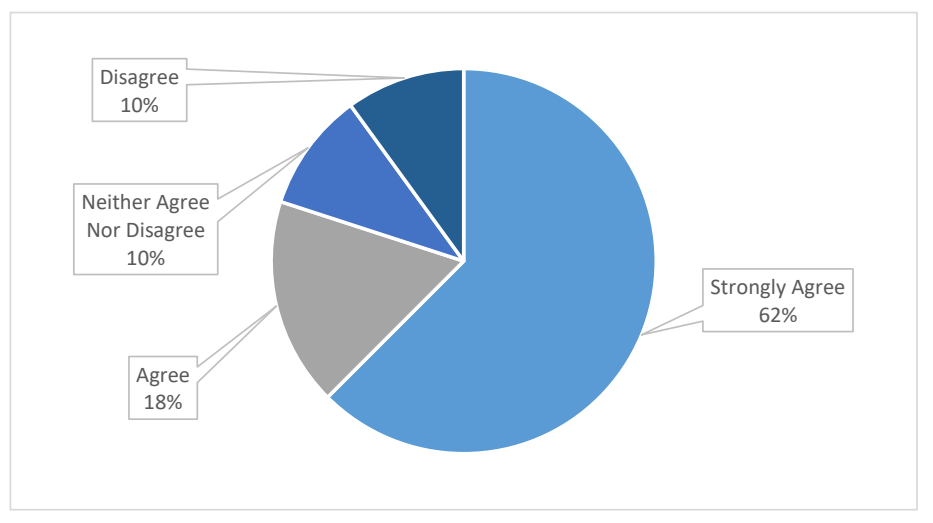

Figure 13. Course dedicated to teaching Project Management

PMBOK: Most practitioners consider important that students have an overview of the PMBOK process groups and areas of knowledge. Another point related to PMBOK frequently raised was the Project Management Triangle, which is a model of the constraints of Project Management relating cost, scope, schedule and quality. A comment that shows this vision is "The course has to address all the process groups described in the PMBOK in general way, to give the student an integrated and complete view of the process, but some should be chosen to deeper view." .

Agile Project Management: Several practitioners raised the topic of agile methodologies, with emphasis on SCRUM, whose use has been increasingly frequent in software projects. For instance, one respondent said "I believe that this knowledge must be complemented by agile methods, in particular scrum, much (mistakenly) used and requested by the current market.". Another comment was "The whole market has a deficit of this content and any information in this sense during graduation is of extreme value."

Practice: Practitioners pointed out the need of more practical content. One response regarding practical activities was that it would be interesting "Having a course that links theory and practice". In general, the answers indicated that the course could use case study (success and failure), dynamics, simulation of a project.

Soft skills: A frequently mentioned topic in the answers was soft skills. Practitioners believe that items such as interpersonal relationship, leadership, crisis management, oral and written communication, presentation techniques, human resource management, customer relationship, communication, conflict resolution and negotiation should be covered in the course.

An interesting comment that can be highlighted concerns the importance of Project Management courses. Practitioners believe that learning Project Management is not only important to be the manager, but also for the learner to understand his or her role in the project.

Overall, there were positive, neutral, and negative comments about a course dedicated to Project Management at the undergraduate level. Some interesting positive comments can be highlighted:

(i) Practitioners strongly believe that Communication Management certainly needs to be addressed in more detail since it is the most difficult discipline to master, and in general it is the root cause of most product failures. According to their experience, projects go out of cost sometimes, lose their deadlines, present poor quality, do not map risks correctly, but in general all this is linked directly or indirectly to poor 
communication between team members, or between team and client, or team and management.

(ii) Practitioners suggest that there should be an approach to the personal aspects of human resources management, especially focused on the management of the team's resources and the relationship among all those involved in the project.

(iii) Practitioners believe that learning Project Management is not only important to be the manager, but also for the learner to understand his or her role in the project.

Concerning the negative and neutral comments, some practitioners do not believe a course dedicated to Project Management is necessary, for instance, such practitioners believe that just approaching methods for Project Management within Software Engineering course would be enough. In addition, there is much prejudice with PMBOK practices by some people who believe the PMBOK is restricted and should be avoided. In short, we noted in the comments that while professionals recognize the importance of PMBOK, they believe that practices do not exactly reflect the reality of the software industry, as PMBOK has many knowledge areas and processes to follow. Therefore, PMBOK is considered a "heavyweight" methodology.

Last, we asked their opinion on graduates from Computing programs having enough technical and soft skills to manage a project. item 4.2 shows that most of the practitioners $(55 \%)$ "Strongly Disagree" or "Disagree" with this statement.

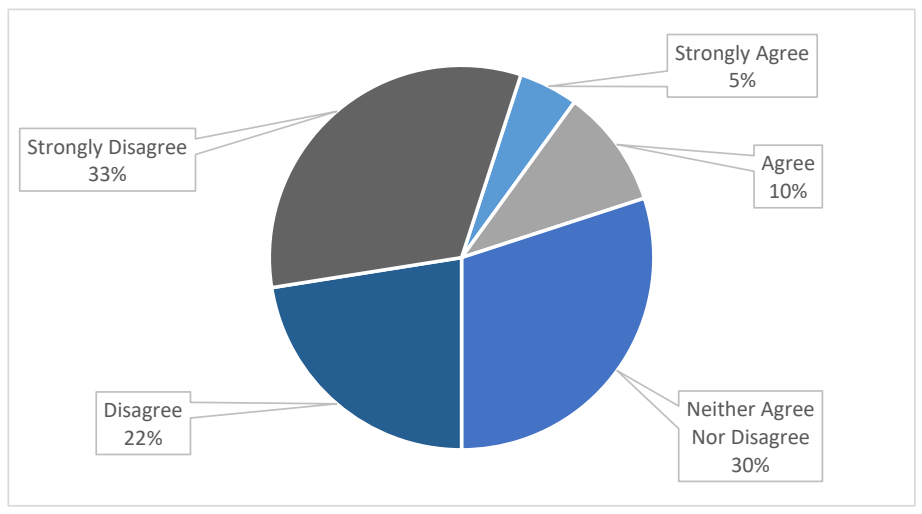

Figure 14. Technical and soft skills to manage a project

Practitioners' opinion indicates that graduates of Computing courses have not been fully prepared for project manager positions. Therefore, it is important to enumerate which technical and main skills have been required by the industry.

\subsection{Main Technical and Soft Skills}

In order to identify more objectively the main technical and soft skills for project managers on a daily basis, they were asked to answer which one(s) they considered essential.

Regarding the technical skills, subsection 4.3 summarizes the results. The three most chosen technical skills were Scope Management, Communications Management and Schedule Management. Some practitioners also added their own answers to complement the given items. The most raised technical skill mentioned was Agile methods.

Regarding the soft skills, results are shown in Figure 4.3. The four most chosen soft skills were Communication, Negotiation, Conflict resolution and Leadership. 


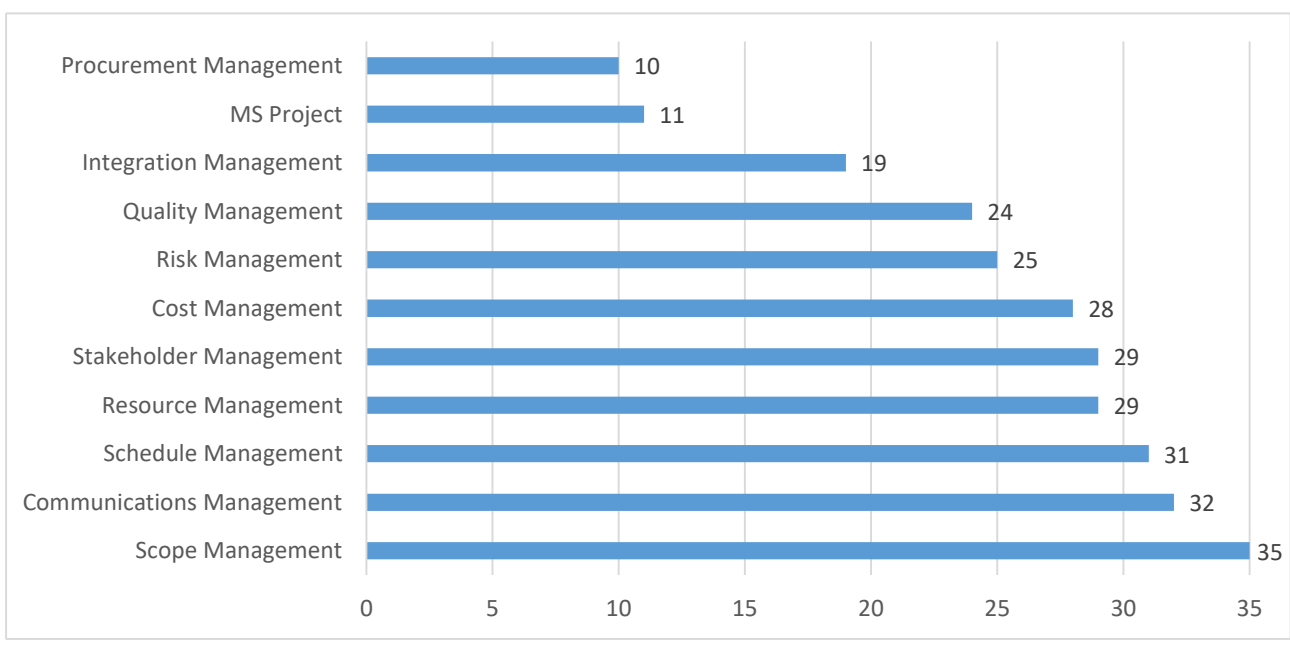

Figure 15. Technical skills of a Software Project Manager

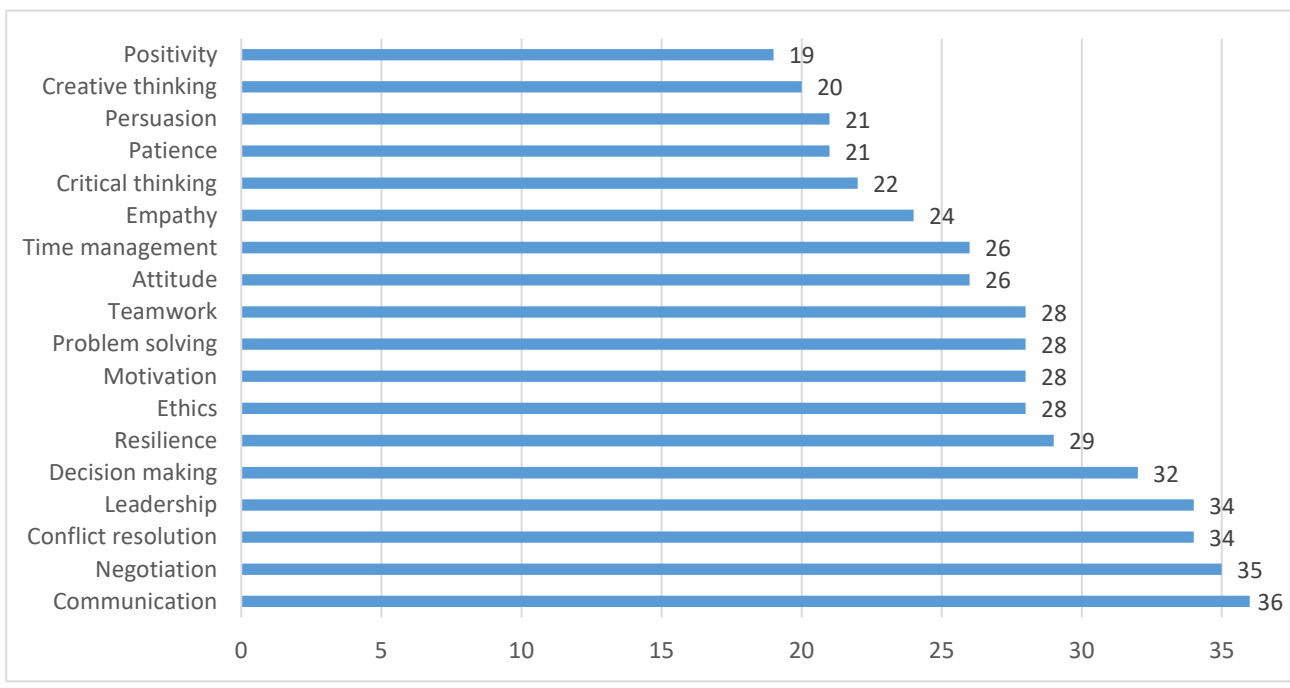

Figure 16. Soft skills of a Software Project Manager

\section{Discussion}

Concerning the first goal, the results shown in Section 4.1 indicate that although most software project managers have graduated from computer programs, they have often looked for complementary courses and certifications. The main search is still for postgraduate programs aiming to complement managerial knowledge that was not properly acquired during undergraduate degree programs. Although some practitioners are PMP-Certified, we noticed that they are not the majority, since the need for a certification in industry has become less common.

We could also verify that a large number of practitioners has become project managers in few years after graduating, but we can still notice those who became project managers after more than five years in a technical role. An interesting point was the variability in practitioners experience as project managers, which contributes positively to the study, since professionals in different moments of their careers can bring complementary contributions to the results.

Concerning the second goal, the results shown in Section 4.2 indicate that there is a large knowledge gap in project management topics. The main reasons for this are: (i) V. $17 \mathrm{~N}^{\circ} 3$, dezembro, 2019 RENOTE DOI: 
not every undergraduate program offers an exclusive course on this topic, being the content taught at a high level in other courses, such as Software Engineering; and (ii) the project management courses offered lack to attend the industry's needs, frequently failing to cover practical activities and develop soft skills.

Finally, the results shown in Section 4.3 address the third goal aimed for this study. Based on the fact that there is knowledge gap in project management, we collected the main technical and soft skills for a project manager, aiming to provide input for the improvement of project management courses.

In general, we can highlight that practitioners iterated the importance of agile methods, soft skills and how their knowledge acquired during undergraduation was below the industry expectations.

\section{Threats to Validity}

To describe the internal validity of empirical results, it is important to exclude or, at least, to explain confounding variables and other sources of potential bias (KITCHENHAM et al. 2002). One potential threat to internal validity (especially construct validity) in questionnaires are ambiguously and poorly-worded questions, which was mitigated by pilot-testing our questionnaire. An additional limitation of questionnaires is the uncertainty whether the participants answer truthfully. We tried to keep this risk low by ensuring the practitioners that the participation is voluntary and that no data is gathered that would allow us to draw conclusions with respect to the identity of the practitioner. Moreover, if people are not willing to be honest, they usually do not volunteer for such a survey. However, this risk can never be excluded totally.

External validity is the extent to which conclusions can be generalized and capture the objectives of the study (KITCHENHAM et al., 2002). It is primarily concerned with the representativeness of the sample for the target population (CIOLKOWSKI et al., 2003). The target population of this study is Software Project Managers. We assume that our findings can be generalized to the population of Software Project Managers who fit these sampling criteria.

\section{Conclusions and Future Work}

In this paper we presented an investigation about knowledge deficiencies in SPM education, considering the industry needs.

In general, the results indicated that there is a number of professionals who seeks postgraduate programs to fill the deficiencies of the undergraduate programs, aiming to act as project managers. Additionally, practitioners reported a lack of hands-on activities and development of soft skills that would make the course more "real world" than they are presented at the undergraduate level.

As future work, we intend use the findings of this work and a survey with software project management educators (FIORAVANTI; BARBOSA, 2019) as an input for the improvement of SPM courses. The main idea is to provide more attractive Software Project Management courses derived from a learning design framework, which focuses on improving relevant technical and soft skills for a Project Manager.

\section{Acknowledgements}

The authors would like to thank the Brazilian funding agencies - São Paulo Research Foundation (FAPESP) under grants \#2018/15163-6 and \#2018/26636-2; and CNPq under grant RENOTE 
\#141010/2018-5. We also thank the practitioners that participated in the survey and the reviewers for their comments.

\section{References}

ACM/IEEE-CS. Computer science curricula 2013. 2013. 〈www.acm.org/education/ CS2013-final-report.pdf $\rangle$.

BASILI, V. R. Software modeling and measurement: the Goal/Question/Metric paradigm, 1992.

CIOLKOWSKI, M. et al. Practical experiences in the design and conduct of surveys in empirical software engineering. In: Empirical methods and studies in software engineering: Springer, 2003. p. 104-128.

FIORAVANTI, M. L.; BARBOSA, E. Outlining Software Project Management Education by Surveying Educators. In: Proceedings of the 49th Annual Frontiers in Education Conference (FIE 2019))Cincinnati, USA: , 2019.

KASUNIC, M. Designing an effective survey, 2005.

KERZNER, H. R. Project management: a systems approach to planning, scheduling, and controlling: John Wiley \& Sons, 2013.

KITCHENHAM, B. et al. An investigation of software engineering curricula. Journal of Systems and Software, v. 74, n. 3, p. 325 - 335, 2005.

KITCHENHAM, B. A.; PFLEEGER, S. L. Personal Opinion Surveys. In: Guide to Advanced Empirical Software Engineering, 2008. p. 63-92.

KITCHENHAM, B. A. et al. Preliminary guidelines for empirical research in software engineering. IEEE Transactions on software engineering, IEEE, v. 28, n. 8, p. 721-734, 2002 .

LETHBRIDGE, T. C. et al. Improving software practice through education: Challenges and future trends. In: Future of Software Engineering, 2007. FOSE '07, 2007. p. 12-28.

MORENO, A. M. et al. Balancing software engineering education and industrial needs. Journal of Systems and Software, v. 85, n. 7, p. 1607 - 1620, 2012. Software Ecosystems.

PMI. A Guide to the Project Management Body of Knowledge - PMBOK® Guide. 6. ed., 2017.

RADERMACHER, A.; WALIA, G. Gaps between industry expectations and the abilities of graduates. In: Proceeding of the 44th ACM Technical Symposium on Computer Science Education (SIGCSE '13). New York, NY, USA: ACM, 2013. p. 525-530. ISBN 978-1-4503-1868-6.

TUZUN, E.; ERDOGMUS, H.; OZBILGIN, I. G. Are computer science and engineering graduates ready for the software industry?: Experiences from an industrial student training program. In: Proceedings of the 40th International Conference on Software Engineering: Software Engineering Education and Training. New York, NY, USA: ACM, 2018. (ICSE-SEET '18), p. 68-77. ISBN 978-1-4503-5660-2. Available at: $\langle$ http://doi.acm.org/10.1145/3183377.3185754〉. 